\title{
Secretory Carcinoma: A Silent Mass Increasing in the Parotid Gland
}

\author{
Cheng-Chieh Lu ${ }^{1}$, Chien-Jui Cheng ${ }^{2,3 *}$, Yu-Chien $\mathrm{Kao}^{4}$, Mei-Chien Chen ${ }^{1}$ \\ ${ }^{1}$ Department of Otolaryngology, Head and Neck Surgery, Shuang Ho Hospital, Taipei Medical University, Taipei, Taiwan; \\ ${ }^{2}$ Department of Pathology, School of Medicine, College of Medicine, Taipei Medical University, Taipei, Taiwan; ${ }^{3}$ Department of \\ Pathology, Taipei Medical University Hospital, Taipei, Taiwan; ${ }^{4}$ Department of Pathology, Shuang Ho Hospital, Taipei Medical \\ University, Taipei, Taiwan
}

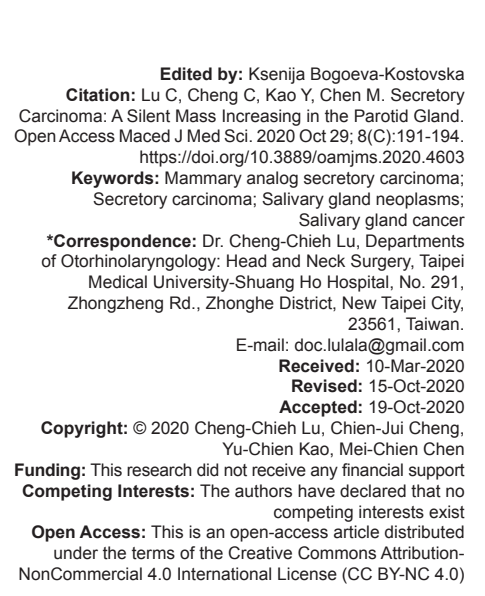

\begin{abstract}
BACKGROUND: Secretory carcinoma (SC) of the salivary gland, also known as mammary analog secretory carcinoma, is a rare tumor in the parotid gland. This kind of tumor is characterized by generally indolent clinical behavior and expression of a break in the ETV6 gene.

CASE REPORT: We present a unique case of secretory carcinoma and show its favorable prognoses.

CONCLUSION: Secretory carcinoma of the salivary gland is a low-grade carcinoma with a favorable prognosis. It has low regional lymph node and distant metastasis potential. Due to the possibility of misdiagnosis, immunohistochemical studies and FISH are suggested. The most effective treatment is complete surgical excision with negative surgical margins.
\end{abstract}

\section{Introduction}

Secretory carcinoma (SC), formerly known as mammary analog secretory carcinoma (MASC), was renamed by WHO in the Classification of Head and Neck Tumors in 2017 [1]. In the beginning, this kind of tumor was first noticed in the breast and was called juvenile breast carcinoma and secretory carcinoma of the breast [2]. In 2010, Skálová found it occurring in the salivary gland and then named it MASC in salivary glands [3]. Secretory carcinoma is a low-grade malignant tumor and usually occurs in salivary glands, especially in the parotid gland (68\%) [4].

It can be confused with acinic cell carcinoma (AciCC) and distinguished by immunohistochemical studies and fluorescence in situ hybridization (FISH). Complete surgical excision of secretory carcinoma is the treatment of choice, while gene fusion data can give us a better understanding of target therapy treatment.

We report a case of secretory carcinoma of the left parotid gland diagnosed and treated in our department. Left superficial parotidectomy was performed and the FISH study revealed a break-apart of ETV6 gene. No local recurrence was observed on physical examination and ultrasound on follow-up for 2 years.

\section{Case Report}

A 37-year-old man presented with a history of a left parotid mass that was gradually increasing in size for 6 months since October, 2017. No tenderness or facial numbness was noticed. On examination, he presented a firm, fixed, and non-tender mass on the left parotid region of about $6 \times 5 \mathrm{~cm}^{2}$. Ultrasound showed a cystic mass and the result of fine-needle aspiration cytology report presented atypical cellular change. Contrast-enhanced computed tomography (CT) was performed for pre-surgical operation planning. One $4.1 \mathrm{~cm}$ cystic mass with irregular wall thickening at the left parotid gland was noticed (Figure 1).

On the basis of radiological and cytological findings, the left side superficial parotidectomy was 

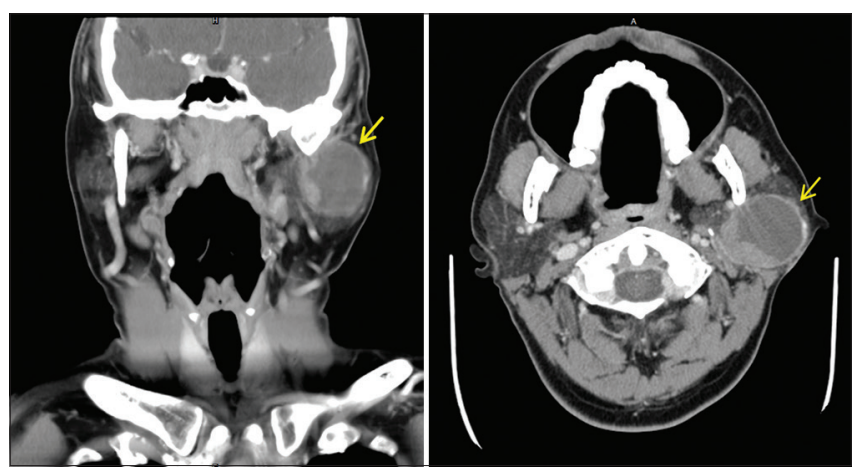

Figure 1: Computed tomography scan of head and neck showing a $4.1 \mathrm{~cm}$ cystic mass (arrow) with irregular wall thickening at the left parotid gland

performed under facial nerve monitoring (Figure 2). Histopathology revealed secretory carcinoma composed of cuboid or columnar epithelial cells (Figure 3). Immunohistochemical studies were positive for S-100 and CK7 and negative for p63, CK5/6, and DOG-1. FISH study revealed a break-apart of ETV6 gene (Figure 4).

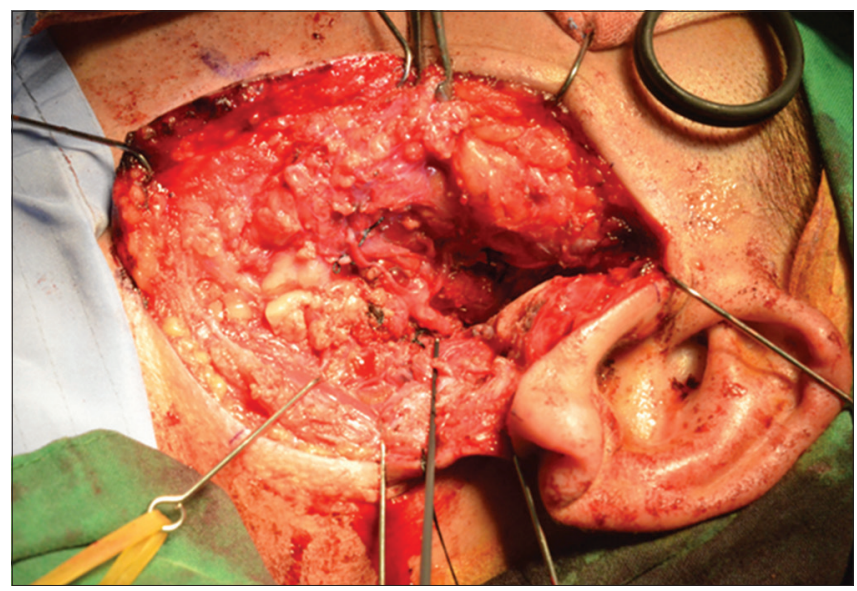

Figure 2: Photo of the surgery demonstrating left superficial parotidectomy with preservation of facial nerve

No local recurrence was observed on physical examination and ultrasound on follow-up for 2 years.

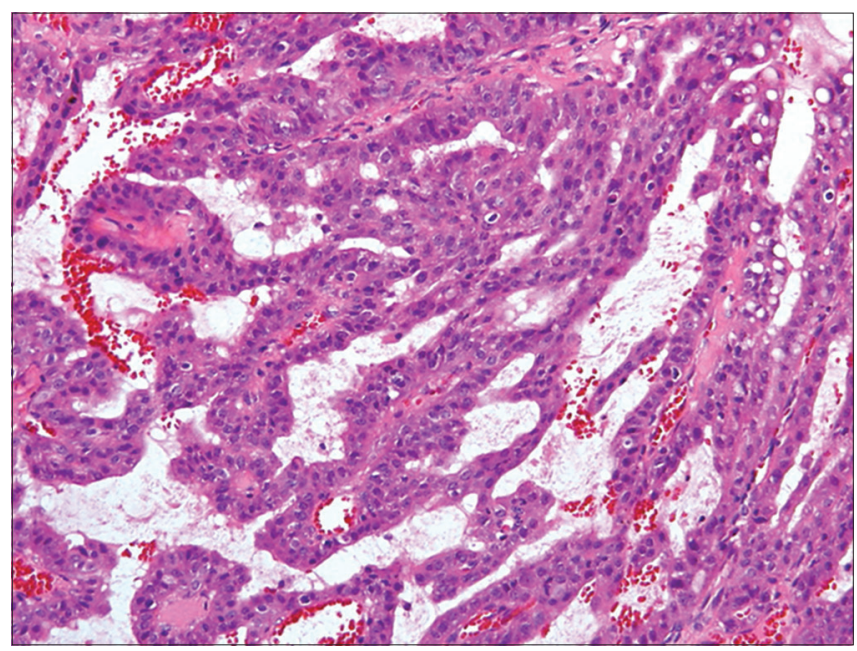

Figure 3: Histopathology revealed secretory carcinoma composed of cuboid or columnar epithelial cells

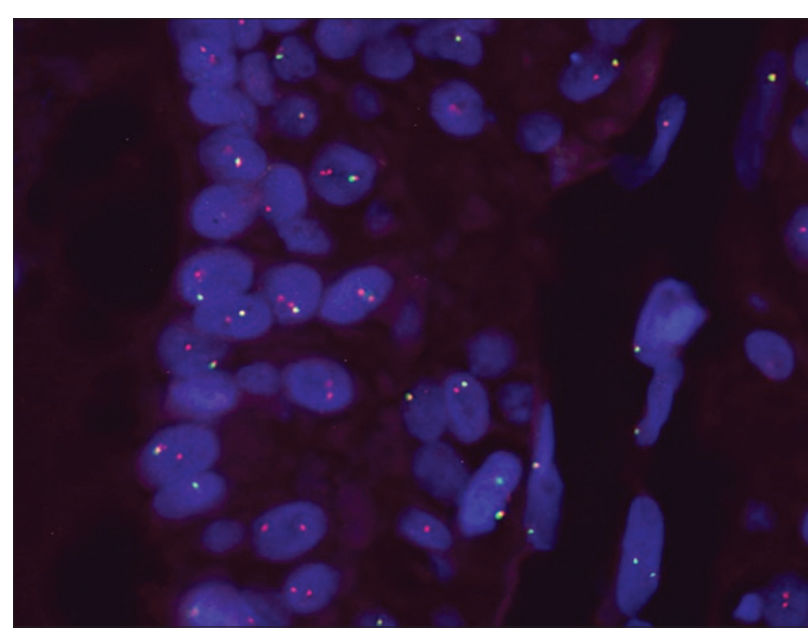

Figure 4: Fluorescence in situ hybridization study showed positive for ETV6 gene rearrangement with loss of 3' signals (green)

\section{Discussion}

Secretory carcinoma of the salivary gland is a rare type of tumor with generally indolent clinical behavior [4]. Its incidence is $<0.5 \%$ in parotid malignant neoplasms [5] and usually presents as an asymptomatic mass in the parotid gland with slight male predilection $(1.5: 1)$ and the age span for SC is wide (5-77 years) [4]. It has also been reported in the nasal cavity, vulva, lacrimal gland [6], eyelid [7], skin [8], thyroid [9], and lung [10]. Most patients with SC present with a slowly growing painless tumor.

The diagnostic plan for SC includes ultrasound and image study (head and neck $\mathrm{CT} /$ magnetic resonance imaging). Although fine-needle aspiration may be performed during ultrasound evaluation, the cytology diagnosis for SC is poor. According to Kai et al., only 2 of 109 cytologists identified SC [11]. Immunohistochemistry and FISH studies using pathologic specimen can yield a definite diagnosis. In immunohistochemistry, SC is positive for S100, mammaglobin, and CK7 and negative for p63, CK5/6, and DOG-1 stains in the literature (Table 1) [12]. By FISH, SC shows ETV6 gene rearrangements. The most well-known fusion partner gene is NTRK3 (more than 90\%) [13]. When fusions happen, the ETV6 gene enrolls - transcriptional regulator gene and the other genes (ex: NTRK3, MET, and RET) enroll a membrane receptor kinase. The above finding can lead to well-designed-target therapy in the literature [14]: We may choose Trk inhibitors (e.g., entrectinib and larotrectinib) for patients with a NTRK3 fusion gene and c-Met inhibitors (e.g., cabozantinib) for patients with a MET fusion gene if systemic therapy is needed [15] (Table 2).

The treatment of choice for SC is complete surgical excision. Due to the low incidence of lymph node involvement, elective neck dissection is not suggested for every case. Neither radiotherapy nor 
chemotherapy is needed after the operation due to its favorable prognosis [4].

Table 1: Comparison of findings between SC and AciCC

\begin{tabular}{|c|c|c|c|c|c|c|}
\hline & \multirow[t]{2}{*}{ Cytology } & \multicolumn{4}{|c|}{ Immunostain } & \multirow{2}{*}{$\begin{array}{l}\text { FISH } \\
\text { ETV6 spitt }\end{array}$} \\
\hline & & Mammaglobin & $\$ 100$ & Vimentin & DOG-1 & \\
\hline sc & Papillary tragment, mucoid background & + & ++ & ++ & - & + \\
\hline AcicC & Cell groups and single cells, granular with nudel background & - & + & + & + & - \\
\hline
\end{tabular}

In our case, the immunohistochemical studies were positive for S-100 and CK7 and negative for p63, CK5/6, and DOG-1. FISH study with a break-apart of ETV6 gene was noticed. The diagnosis of MASC was confirmed.

Table 2: The gene rearrangements of $\mathrm{SC}$ and the suggestive target therapy

\begin{tabular}{|c|c|c|}
\hline \hline Transcriptional regulator gene & Membrane receptor kinase-type & Treatment \\
\hline \multirow{3}{*}{ ETV6 } & NTRK3( $9 \mathbf{9 0} \%)$ & Entrectinib and larotrectinib \\
\cline { 2 - 3 } & MET & RXDX105, LOXO292 \\
\cline { 2 - 3 } & RET(2-5\%) & Cabozantinib \\
\hline
\end{tabular}

Although MASC is considered a low-grade malignant tumor in most cases, recurrence and disease dissemination still happen sometimes. Long-term follow-up is suggested.

\section{Conclusion}

Secretory carcinoma of the salivary gland is a low-grade carcinoma with a favorable prognosis. It has low regional lymph node and distant metastasis potential. Due to the possibility of misdiagnosis, immunohistochemical studies and FISH are suggested. The most effective treatment is complete surgical excision with negative surgical margins. $\mathrm{FISH}$ is recommended for SC patients, not only to provide definite result but also to obtain information for further target therapy if needed.

\section{Ethical Statement}

The paper had complied with the guidelines for human studies and animal welfare regulations. The authors state that subjects have given their informed consent and that the study protocol has been approved by the Institute's Committee on Human Research (TMU-JIRB number: N201812013). The authors also state that animal experiments conform to institutional standards.

\section{References}

1. Khalele BA. Systematic review of mammary analog secretory carcinoma of salivary glands at 7 years after description. Head Neck. 2017;39(6):1243-8. https://doi.org/10.1002/hed.24755 PMid:28370824

2. McDivitt RW, Stewart FW. Breast carcinoma in children. JAMA 1966;195(5):388-90. https://doi.org/10.1001/jama.195.5.388 PMid:4285563

3. Kravtsov O, Hunt B, Peterson J, Carrillo L, Bonneau P, Giorgadze T. Secretory carcinoma of the parotid with adenoid cystic carcinoma cytological pattern: A cytological-pathological correlation with literature review. Ann Diagn Pathol. 2018;33:5861. https://doi.org/10.1016/j.anndiagpath.2017.12.006 PMid:29566949

4. Boon E, Valstar MH, van der Graaf WT, Bloemena E, Willems SM, Meeuwis CA, et al. Clinicopathological characteristics and outcome of 31 patients with ETV6-NTRK3 fusion gene confirmed (mammary analogue) secretory carcinoma of salivary glands. Oral Oncol. 2018;82:29-33. https://doi.org/10.1016/j. oraloncology.2018.04.022 PMid:29909898

5. Takahama A Jr., de Almeida OP, Kowalski LP. Parotid neoplasms: Analysis of 600 patients attended at a single institution. Braz J Otorhinolaryngol. 2009;75(4):497-501. https://doi.org/10.1590/ s1808-86942009000400005

PMid: 19784416

6. Hyrcza MD, Andreasen S, Melchior LC, Tucker T, Heegaard S, White VA. Primary secretory carcinoma of the lacrimal gland Report of a new entity. Am J Ophthalmol. 2018;193:178-83. https://doi.org/10.1016/j.ajo.2018.06.019 PMid:29963997

7. Bao Y, Li J, Zhu Y. Mammary analog secretory carcinoma with ETV6 rearrangement arising in the conjunctiva and eyelid. Am J Dermatopathol. 2018;40(7):531-5. https://doi.org/10.1097/ dad.0000000000001062 PMid:29251639

8. Moore RF, Cuda JD. Secretory carcinoma of the skin: Case report and review of the literature. JAAD Case Rep. 2017;3(6):559-62. https://doi.org/10.1016/j.jdcr.2017.07.003 PMid:29159250

9. Liao H, Khan A, Miron PM, Cornejo KM. Mammary analogue secretory carcinoma of the thyroid mimicking locally advanced papillary thyroid carcinoma: A rare case report. Int J Surg Pathol. 2018;26(5):459-63. https://doi.org/10.1177/1066896917747076 PMid:29228842

10. Huang T, McHugh JB, Berry GJ, Myers JL. Primary mammary analogue secretory carcinoma of the lung:Acase report. Hum Pathol. 2018;74:109-13. https://doi.org/10.1016/j.humpath.2017.10.027 PMid:29104113

11. Kai $K$, Minesaki A, Suzuki $K$, Monji $M$, Nakamura $M$, Tsugitomi $\mathrm{H}$, et al. Difficulty in the cytodiagnosis of mammary analogue secretory carcinoma: Survey of 109 cytologists with a case originating from a minor salivary gland. Acta Cytol. 2017;61(6):469-76. https://doi.org/10.1159/000477390 PMid:28738326

12. Badlani J, Gupta R, Balasubramanian D, Smith J, Luk P, Clark J. Primary salivary gland malignancies: A review of clinicopathological evolution, molecular mechanisms and management. ANZ J Surg. 2018;88(3):152-7. https://doi. org/10.1111/ans.14201

PMid:28982213

13. Skalova A, Stenman G, Simpson RH, Hellquist H, Slouka D, 
Svoboda $\mathrm{T}$, et al. The role of molecular testing in the differential diagnosis of salivary gland carcinomas. Am J Surg Pathol. 2018;42(2):e11-27. https://doi.org/10.1097/ pas. 0000000000000980

PMid:29076877

14. Rooper LM, Karantanos T, Ning Y, Bishop JA, Gordon SW, $\mathrm{Kang} \mathrm{H}$, et al. Salivary secretory carcinoma with a novel ETV6MET fusion: Expanding the molecular spectrum of a recently described entity. Am J Surg Pathol. 2018;42(8):1121-6. https:// doi.org/10.1097/pas.0000000000001065

PMid:29683815

15. Skalova A, Vanecek T, Martinek P, Weinreb I, Stevens TM, Simpson $\mathrm{RH}$, et al. Molecular profiling of mammary analog secretory carcinoma revealed a subset of tumors harboring a novel ETV6-RET translocation: Report of 10 cases. Am J Surg Pathol. 2018;42(2):234-46. https://doi.org/10.1097/ pas.0000000000000972

PMid:29076873 